\title{
The contributions of handedness and working memory to episodic memory
}

\author{
Aparna Sahu $^{1} \cdot$ Stephen D. Christman ${ }^{1} \cdot$ Ruth E. Propper ${ }^{2}$
}

Published online: 3 June 2016

(C) Psychonomic Society, Inc. 2016

\begin{abstract}
Past studies have independently shown associations of working memory and degree of handedness with episodic memory retrieval. The current study takes a step ahead by examining whether handedness and working memory independently predict episodic memory. In agreement with past studies, there was an inconsistent-handed advantage for episodic memory; however, this advantage was absent for working memory tasks. Furthermore, regression analyses showed handedness, and complex working memory predicted episodic memory performance at different times. Results are discussed in light of theories of episodic memory and hemispheric interaction.
\end{abstract}

Keywords Handedness $\cdot$ Working memory $\cdot$ Episodic memory $\cdot$ Regression analysis

Episodic memory is a long-term memory system that is unique to an individual and is based on past happenings, specific in time and place (Tulving, 1972, 1993). It is a widely studied cognitive process assessed by tests of recall and recognition for previously learned material (Friedman \& Johnson, 2000). Theories of episodic memory retrieval, such as the search for associative memory (SAM; Raaijmakers \& Shiffrin, 1981) and the retrieval context framework (Kahana, Howard, \& Polyn, 2008; Kahana, Howard, Zaromb, \&

Stephen D. Christman

stephen.christman@utoledo.edu

1 Department of Psychology, University of Toledo, 6801 W. Bancroft Ave., Toledo, $\mathrm{OH} 43606$, USA

2 Department of Psychology, Montclair State University, 1 Normal Ave., Montclair, NJ 07043, USA
Wingfield, 2002) suggest that episodic memory retrieval is successful when an individual also retrieves contextual cues that were used during the encoding phase Fig. 1.

These theories make an indirect reference to the role of working memory (WM) as a facilitator during memory processes. Studies have shown that low WM capacity individuals report fewer items at free recall, show more intrusions from previous trials during a list-learning task, recall at a slow rate (Unsworth, 2007) and are disorganized in their approach during the recall phase (Spillers \& Unsworth, 2011). In both incidental and intentional learning conditions, high WM capacity individuals performed significantly better (Unsworth \& Spillers, 2010) because of increased use of contextual cues and maintaining the same cues during both encoding and retrieval processes (Spillers \& Unsworth, 2011; Unsworth, Brewer, \& Spillers, 2011; Unsworth, \& Spillers, 2010). These behavioral findings show the role of WM in longterm memory processing. Neuroimaging studies show overlaps in the activation of prefrontal areas during WM and episodic memory retrieval tasks (Cabeza, Dolcos, Graham, \& Nyberg, 2002; Ranganath, Johnson, \& D'Esposito, 2003). This could imply that those brain regions perform important functions that are relevant and required for both memory processes, such as maintaining and updating information, and monitoring and selecting responses (Nyberg, Marklun, Persson, Cabeza, Forkstam, Petersson, \& Ingvar, 2003). Thus, it appears that both WM and episodic memory share some commonality making the two systems codependent on each other.

From an individual difference perspective, age and gender differences in WM and memory retrieval processes have been extensively studied and reported in the literature. For instance, older individuals show a decline in delayed memory recall (Cabeza et al., 1997; Craik \& McDowd, 1987; Kliegel \& Lindenberger, 1993). Increase in age is related to a decline 


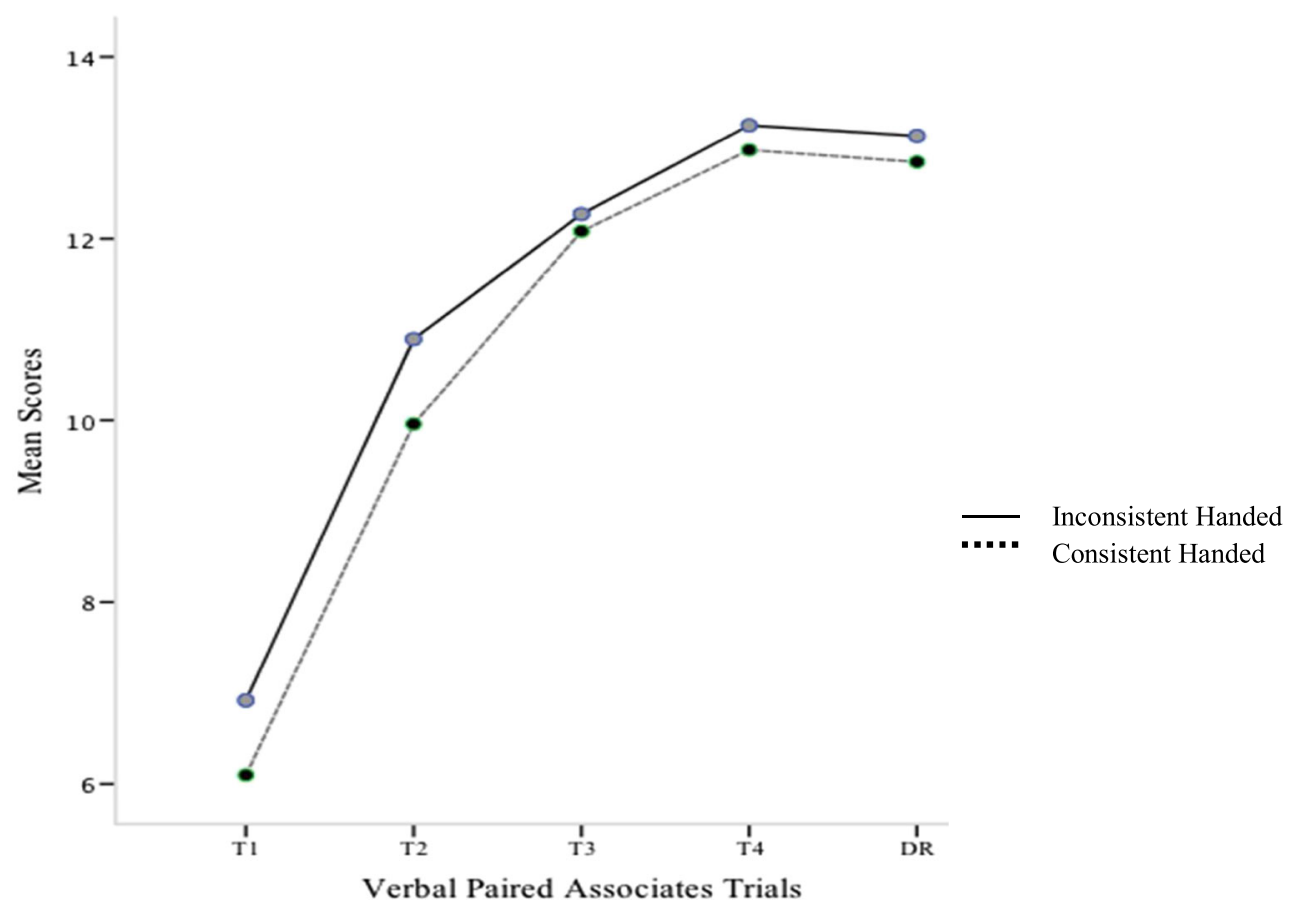

Fig. 1 Performance across paired associates trials between handedness groups

in WM capacity (Dobbs \& Rule, 1989; Salthouse \& Babcock, 1991). A study by Myerson, Emery, White, and Hale, (2003) found the presence of a curvilinear relationship between aging and performance on the letter-number sequencing test (LNS) of the Wechsler Memory Scale- Third Edition battery. They proposed that in comparison to the digit-span performance, LNS performance showed a greater decline with increased age, probably due to a greater deterioration in executive functioning that underlies LNS performance. In terms of gender differences, a female advantage in episodic memory retrieval is predominantly reported (e.g., Geffen, Moar, O'Hanlon, Clark, \& Geffen, 1990; Herlitz, Nilsson, \& Bäckman, 1997; Herlitz \& Rehnman, 2008; Hultsch, Masson, \& Small, 1991). However, there are mixed findings about the presence of gender differences in WM (Loring-Meier \& Halpern, 1999; Lynn \& Irwing, 2008; Schmidt et al., 2009).

Recently, individual differences in interhemispheric interaction via the corpus callosum have been considered as another variable influencing episodic memory retrieval. Specifically, degree of handedness has been used as a behavioral proxy for this variable, involving comparisons between people who report using their dominant hand consistently across tasks and people who report using their nondominant hand for more than one common activity.

Christman and colleagues (Christman \& Propper, 2010; Prichard, Propper, \& Christman, 2013) theorize that inconsistent-handers are at an advantage during episodic memory retrieval because, compared to consistent-handers, inconsistent-handers have relatively greater access to the right hemisphere and possess greater interhemispheric communication. The theory is supported by neurological findings, such as the involvement of the left prefrontal areas during encoding of verbal information and right prefrontal areas during retrieval of the same information (Tulving, Kapur, Craik, Moscovitch, \& Houle, 1994), and studies showing a negative correlation between degree of handedness and volume of the corpus callosum, indicating significantly larger callosal volumes with increasing inconsistent-handedness (Habib et al., 1991; Luders et al., 2010; Witelson, 1985; Witelson \& Goldsmith, 1991).

Furthermore, electrophysiological evidence supporting the association between inconsistent-handedness and greater access to the right hemisphere is provided by two recent studies. Ashworth, Ciorciari, and Stough (2008) studied the relationship between a self-report measure of the psychological phenomenon of "dissociation," a defense mechanism process against psychological trauma that results in a disconnection with one's identity, memories, and perceptions about the environment and laterality measures of handedness and EEG activity. They found that inconsistent-handers who scored low on the dissociation scale (in other words, they reported being connected with their experiences, memories, and environment) were right lateralized within the EEG beta band across the frontal areas; this EEG parameter is normally reflective of active thinking, and alertness. Interestingly, consistent handers who scored low on the dissociation scale were left lateralized on the same EEG spectrum. Propper, Pierce, Geisler, Christman, and Bellorado (2012), showed a relation between inconsistent-handedness and decreased EEG alpha band activity (i.e., increased excitation/activation) over the 
right hemisphere. In view of these findings, it could therefore be speculated that inconsistent-handers possess greater volumes of the corpus callosum that aids in greater interhemispheric interaction and therefore in greater right hemispheric processing, and this results in a significantly better recall of episodic memories in inconsistent-handers relative to consistent-handers.

Studies have shown that inconsistent-handers have superior episodic retrieval of both lab-based (Chu, Abeare, \& Bondy, 2012; Lyle, Hanaver-Torrez, Hackländer, \& Edlin, 2012) and real-world memories (Propper, Christman, \& Phaneuf, 2005), as well as better source memory (Lyle, McCabe, \& Roediger, 2008; Parker \& Dagnall, 2010), fewer false memories (Christman, Propper, \& Dion, 2004), a greater proportion of "remember" relative to "know" responses in recognition memory (Propper \& Christman, 2004), an earlier offset of childhood amnesia (Christman, Propper, \& Brown, 2006), better memory for prior hand usage (Edlin, Carris, \& Lyle, 2013), better learning of foreign vocabulary (Kempe, Brooks, \& Christman, 2009), and better incidental learning (Alipour, Aerab-Sheybani, \& Akhondy, 2012; Christman \& Butler, 2011).

Based on the relations between both WM and handedness to episodic memory retrieval, the current study was undertaken to answer the following: a) Given that degree of handedness is associated with enhanced memory retrieval, is there an underlying association between handedness and WM as well? We considered two WM tasks - digit span of the Wechsler Adult Intelligence Scale-Fourth Edition (WAIS-IV; Wechsler, 2008), a measure for immediate memory span, to represent simple WM, because it possesses only the storage component (Shelton, Elliott, Hill, Calamia, \& Gouvier, 2009) that requires maintaining information over a short period (Unsworth, \& Engle, 2007). A note about the digit-span task - it consists of two components, forward and backward spans. Whereas forward span simply requires the recall of stimuli in the serial order in which it was presented, backward span involves recall of stimuli in the reverse order. It has therefore been suggested that the backward condition is dependent on the phonological loop and the central executive, which is reflected in the form of greater activation of additional prefrontal and frontal areas bilaterally (Li, Qin, Zhang, Jiang, \& Yu, 2012). Despite these evidences, several studies show that both spans significantly account for the storage component (Bowden, Petrauskas, Bardenhagen, Meade, \& Simpson, 2013; Shelton et al., 2009; Wilde, Strauss, \& Tulsky, 2004). In the current study, the two components were analyzed separately to check for handedness differences, if any.

The second WM task was the letter-number-sequencing (LNS) test of the WAIS-IV, which is a standardized test to measure WM. It is taken to measure complex WM, as it involves not only the storage component but also the manipulation component that requires the recruitment of additional cognitive resources (Aben, Stapert, \& Blokland, 2012). The LNS test shares a significantly moderate correlation (between 0.40 to 0.45 ) with laboratory-based WM tasks of operation span, listening span, and the modified lag span (Shelton et al., 2009). Although literature suggests that both the digitspan and LNS tests measure WM (Hill, Elliott, Shelton, Pella, O'Jile, \& Gouvier, 2010), there is evidence that the LNS also depends on executive functioning, attention, processing speed, and spatial abilities (Crowe, 2000; Egeland, 2015; Haut, Kuwabara, Leach, \& Arias, 2000). Furthermore, complex WM tasks are shown to be better predictors of higher order cognitive abilities than are simple WM tasks (Bayliss, Jarrold, Baddeley, \& Gunn, 2003). In view of these reasons, the two WM tasks were considered separately.

b) Given that both increased WM capacity and inconsistent-handedness are associated with enhanced episodic retrieval, what is the nature of their relationship? Do both predict episodic retrieval? Episodic retrieval in the current study was examined by means of the performance on the paired words test of the Wechsler Memory Scale-Fourth Edition (WMS-IV; Wechsler, 2009).

\section{Method}

\section{Participants}

Data were collected from 210 undergraduate participants enrolled in an introductory psychology course in exchange for extra credit. Three participants were excluded from the analyses because their ages were more than five standard deviations from the sample mean. Data from 207 (females $=119$, $M_{\text {age }}=19.18$ years, $S D=1.36$, age range $=18-27$ years) were considered for the analyses. The study protocol was approved by the local internal review board (IRB).

\section{Materials}

Digit-span and the letter-number sequencing tests of the WAIS-IV (Wechsler, 2008) were administered to measure simple and complex WM, respectively. Verbal paired associates (VPA) test of the WMS-IV (Wechsler, 2009) was administered to assess retrieval at immediate (which consisted of four trials) and delayed (i.e., after a gap of 12-16 minutes following the immediate recalls) intervals. The standardized procedures for these tests were followed.

Handedness was assessed using the Edinburgh Handedness Inventory (EHI; Oldfield, 1971). The EHI is a self-report measure that assesses hand preference for common gross motor activities, such as writing, throwing, or using a pair of scissors. Following the recommendations of Dragovic (2004) and Edlin et al. (2015), we used a modified version of the EHI, characterized by the following changes: "Using a 
broom" was replaced with "combing hair"; "opening a box lid" was replaced with "opening a jar"; and a 5-point response scale was used, with the assignment of the following scores: Always right (+10), usually right $(+5)$, no preference $(0)$, usually left (-5), and always left (-10).

\section{Procedure}

Participants were tested individually in a 30-minute session. After signing the informed consent form, the standardized measures were administered per the test protocol. The verbal paired-associates test is a test of recall for word associations and consists of 14 pairs of words (of which 10 pairs were unrelated words). During the learning immediate-recall phase, each pair was read by the experimenter at a rate of 3 seconds per pair, and after listening to all pairs, the first word of each pair was provided and the participant was required to recall the second word. The learning of the word pairs took place over four trials. The correct answer was provided in case the participant gave an incorrect response or no response. Delayed recall for the test was taken after a span of 12 to 16 minutes after the fourth trial of the immediate recall. This time gap was used for administering the WM tasks (these were counterbalanced) and the EHI.

For digit span, each number was read out loud at a rate of one number per second. Two trials were presented for each string of numbers. The maximum possible raw score on the forward span is 9 , whereas on backward span it is 8 (minimum $=2$ for both spans). In the letter-number sequencing task, a series of alternating letters and numbers were read out loud at a rate of one per second. Participants were asked to recall the numbers and letters separately in an ascending order (e.g., the participant was read the following series, 1-C-4-F-7-Z-2, and was expected to report the stimuli in the following order: 1, 2, 4, 7, C, F, Z. Per the standardized version, recalling the letters first and then the numbers was also accepted and scored accordingly). Each series of letters and numbers had three trials. Successive series increased by one upon successfully completing the three trials (e.g., the series begins with two letters and two numbers, followed by three letters and three numbers, and so on). The maximum score that could be obtained on this test is 30 (minimum $=3$ ).

As practiced in past studies, handedness classification was determined using the median-split method. Christman et al. (2004) have defined inconsistent-handers as those scoring below the median score, whereas those who score above the median are categorized as consistent-handers. Raw scores were first converted into absolute scores and a median split was determined. The median score was 80 , and participants were classified in the two groups - inconsistent-handers with scores below $80(n=85)$, and consistent-handed with scores of 80 and above $(n=122)$.

\section{Results}

Statistical analyses were performed using IBM SPSS software Version 21.0. All data were screened for outliers. Delayed recall scores on the VPA were grossly skewed. This was the case because of the ceiling effect in performance wherein a majority of the participants show an above average rate of recall. Given the nature of this data, raw scores in original form (i.e., they were not log transformed) were utilized for the analyses.

\section{Episodic memory analysis: VPA}

A 2 (handedness) $\times 2$ (gender) $\times 6$ (VPA trial: Trial 1 to 5 and delayed recall) mixed ANOVA was conducted to examine the main and interaction effects of individual differences and episodic memory. An interaction effect between handedness and VPA trial was present, $F(3,540)=3.276, p=.03$, partial $\eta^{2}=$ 0.016 . Test of simple main effects were conducted to qualify this effect. As seen in Table 1, inconsistent-handers showed higher scores on the VPA but significantly differed from consistent-handers on Trial $1, F(1,205)=5.41, p=.02$, and Trial 2, $F(1,205)=6.87, p=.01$. Handedness differences were absent for Trial 3, $F(1,205)=0.39, p=.53$, Trial 4, $F(1,205)=1.58, p=.21$, and delayed recall, $F(1,205)=$ $1.57, p=.21$. Interaction effects were absent for gender and episodic recall, $F(3,540)=1.68, p=.18$, partial $\eta^{2}=.008$, and handedness, gender, and episodic recall, $F(3,540)=0.62, p=$ .59 , partial $\eta^{2}=.003$. Significant main effects were present for handedness, $F(1,203)=4.29, p=.04$, partial $\eta^{2}=.02$, with an inconsistent-handedness advantage, and episodic recall, $F(3$, $540)=830.31, p=.001$, partial $\eta^{2}=.804$. Pairwise comparisons for VPA trials showed significant differences between trials $(p=.001)$, except in the case of difference between Trial 4 and delayed recall $(p=.93)$.

\section{Simple WM analysis: Digit span}

A 2 (gender) $\times 2$ (handedness) $\times 2$ (span: forward vs. backward) mixed ANOVA was conducted to assess the roles of handedness and gender on simple WM ability as assessed by the digit-span forward and backward tasks from the WAIS-IV battery. There was a significant main effect for digit span, $F(1$, 203) $=347.34, p=.001$, partial $\eta^{2}=.64$, with digit-span forward performance $(M=6.90)$ being significantly better than backward performance $(M=5.31)$. Means and standard errors of the test performance are presented in Table 1. Main effects for gender, $F(1,203)=0.44, p=.51$, partial $\eta^{2}=.002$, and handedness, $F(1,203)=1.24, p=.27$, partial $\eta^{2}=.006$, were also not significant. Interaction effects were absent between digit span and gender, $F(1,203)=0.68, p=.41$, partial $\eta^{2}=.003$, gender and handedness, $F(1,203)=0.86, p=.77$, partial $\eta^{2}=.003$, digit span and handedness, $F(1,203)=0.75$, 
Table 1 Mean $(S E)$ of the outcome variables used in the study factored by handedness groups $(N=207)$

\begin{tabular}{lcc}
\hline Variables & Inconsistent-Handed & Consistent-Handed \\
\hline DS-Forward & $6.80(0.12)$ & $6.94(0.10)$ \\
DS-Backward & $5.25(0.12)$ & $5.36(0.09)$ \\
Total LNS scores & $21.55(0.27)$ & $21.67(0.26)$ \\
Trial 1 VPA & $6.92(0.26)$ & $6.10(0.23)$ \\
Trial 2 VPA & $10.89(0.25)$ & $9.96(0.25)$ \\
Trial 3 VPA & $12.27(0.22)$ & $12.08(0.20)$ \\
Trial 4 VPA & $13.25(0.13)$ & $12.98(0.16)$ \\
Total VPA scores & $43.33(0.72)$ & $41.16(0.70)$ \\
VPA-Delayed recall & $13.13(0.16)$ & $12.84(0.16)$ \\
\hline
\end{tabular}

Note. VPA Verbal paired associates, DS Digit span, LNS Letter-number sequencing, $S D$ Standard deviation.

$p=.78$, partial $\eta^{2}<.001$, and digit span, gender, and handedness, $F(1,205)=0.002, p=.96$, partial $\eta^{2}<.001$.

\section{Complex WM analysis: Letter-number sequencing}

A $2 \times 2$ between-subjects ANOVA with handedness and gender as factors was conducted on LNS total scores. There was a main effect of gender, $F(1,203)=8.50, p=.004$, partial $\eta^{2}=$ .04 , with males $(M=22.14)$ outperforming females $(M=$ 21.18 ) in complex working memory. Main effect of handedness, $F(1,203)=0.43, p=.51$, partial $\eta^{2}=.002$, and interaction effect between handedness and gender, $F(1,203)=0.15$, $p=.70$, partial $\eta^{2}=.001$ were absent. Overall, handedness differences were not present in WM tasks.

\section{Regression analyses: Handedness, WM, and episodic retrieval}

Multiple regression analysis were conducted to evaluate whether handedness and WM predict episodic retrieval. Performance on Trial 1, total VPA scores and delayed recall scores were considered as the outcome variables representing episodic recall. These three variables were chosen because (a) VPA Trial 1 is the purest measure of immediate episodic memory because it does not involve the practice and repetition effects in subsequent trials, (b) total VPA scores represent an aggregate measure of VPA performance overall, and (c) delayed recall represents a pure measure of long-term episodic recall. Separate regression analyses were therefore conducted using continuous absolute scores of handedness, digit-span forward and backward scores, and LNS total scores as predictors. Correlations between the variables are presented in Table 2, and low to moderate correlations are present between the predictor and outcome variables.

Results of the multiple regression analyses on the three outcome variables for episodic memory are summarized in Table 3 . Handedness was a significant predictor for trial one $(p=.04)$ of the VPA and the model accounted for $5.3 \%$ of the variability in Trial 1 performance, $R^{2}=0.053, F(3,202)=2.85, p=.03$. The model indicated that the lower the handedness score, the higher was the recall on Trial 1. In other words, increasing inconsistenthandedness was significantly associated with greater recall of word pairs when presented for the first time. Complex WM, as measured by LNS performance, showed an emerging trend for predicting Trial 1 performance; however, this narrowly failed to reach significance $(p=.06)$. Digit forward $(p=.82)$ and backward $(p=.28)$ spans failed to significantly predict recall at Trial 1.

The full regression model accounted for $5.9 \%$ of the variability in performance, $R^{2}=0.059, F(2,202)=3.16, p=.01$. Regression analysis on the total scores on the word pairs as the outcome variable failed to find any handedness effect $(p=$ .12). LNS, or complex WM, was a significant predictor for performance across trials $(p=.05)$; however, digit forward ( $p$ $=.82)$ and backward $(p=.28)$ were not significant.

Finally, none of the independent variables significantly predicted delayed recall, $R^{2}=0.03, F(2,202)=1.49, p=.21$.

\section{Discussion}

The results of the current study can be summarized simply: (a) no handedness differences were observed

Table 2 Bivariate correlations between variables for the regression analysis $(N=207)$

\begin{tabular}{|c|c|c|c|c|c|c|c|}
\hline Variables & EHI score & Digit span forward & Digit span backward & LNS total & First trial (VPA) & Total scores (VPA) & Delayed recall (VPA) \\
\hline EHI score & - & & & & & & \\
\hline Digit span forward & 0.10 & - & & & & & \\
\hline Digit span backward & 0.10 & $0.40^{* *}$ & - & & & & \\
\hline LNS total & 0.06 & $0.47^{* *}$ & $0.46^{* *}$ & - & & & \\
\hline First trial (VPA) & $-0.13^{*}$ & 0.10 & 0.12 & $0.18^{* * *}$ & - & & \\
\hline Total scores (VPA) & -0.09 & 0.12 & 0.12 & $0.20^{* *}$ & $0.79^{* *}$ & - & \\
\hline Delayed recall (VPA) & -0.04 & 0.10 & 0.12 & $0.15^{*}$ & $0.43^{* *}$ & $0.77^{* *}$ & - \\
\hline
\end{tabular}

Note. EHI Edinburgh Handedness Inventory, LNS Letter-number sequencing task, VPA Verbal paired associates

$* p=.05 . * * p=.01$. 
Table 3 Summary of regression analyses for episodic recall using handedness and WM as predictors $(N=207)$

\begin{tabular}{|c|c|c|c|c|c|c|c|c|c|}
\hline \multirow[b]{2}{*}{ Variables } & \multicolumn{3}{|c|}{ Trial1 - VPA } & \multicolumn{3}{|c|}{ Total scores - VPA } & \multicolumn{3}{|c|}{ Delayed recall - VPA } \\
\hline & $B$ & $S E B$ & $\beta$ & $B$ & $S E B$ & $B$ & $B$ & $S E B$ & $\beta$ \\
\hline Handedness & -0.02 & 0.008 & $-0.15^{*}$ & -0.04 & 0.02 & -0.11 & -0.01 & 0.01 & -0.06 \\
\hline DS-Forward & 0.02 & 0.19 & 0.01 & 0.12 & 0.53 & 0.02 & 0.04 & 0.12 & 0.03 \\
\hline DS-Backward & 0.12 & 0.19 & 0.05 & 0.61 & 0.56 & 0.10 & 0.11 & 0.13 & 0.07 \\
\hline LNS & 0.16 & 0.08 & 0.16 & 0.48 & 0.24 & $0.16^{*}$ & 0.07 & 0.05 & 0.10 \\
\hline$R^{2}$ & & 0.053 & & 0.059 & & 0.029 & & & \\
\hline$F$ & & $2.85^{*}$ & & $3.16^{* *}$ & & 1.49 & & & \\
\hline
\end{tabular}

Note. LNS Letter-number sequencing task, VPA Verbal paired associates.

$* p<.05 . ; * p<.01$.

for either simple or complex WM tasks; (b) a significant inconsistent-handed advantage in episodic retrieval was obtained using a paired-associates learning task, replicating prior findings of inconsistent-handed advantages in episodic memory; and (c) regression analyses indicated that WM capacity predicted episodic retrieval during Trial 1, whereas inconsistent-handedness predicted episodic retrieval over trials.

Consistent with findings from past studies, a significant inconsistent-handed advantage in episodic recall was found. These results may reflect that inconsistenthanders have a greater ability to retrieve explicit episodic information during recall than consistent- handers do (Lyle et al., 2008; Propper \& Christman, 2004). This gains support from studies that show an inconsistenthanded advantage in increased source monitoring (Christman et al., 2004), deeper levels of processing, and/or better incidental learning (Alipour et al., 2012; Christman \& Butler, 2011). These findings are consistent with the idea that inconsistent-handers show a superior recall of episodic information, likely as a result of greater interhemispheric interaction and increased access to the right hemisphere.

Behavioral findings do not show handedness differences in immediate memory span, a measure of simple WM, and this is in agreement with past studies with typical subjects (Gunstad, Spitznagel, Luyster, Cohen, \& Paul, 2007; Lyle et al., 2008). In the present study, a complex WM paradigm was also used, but it too did not yield handedness differences. It is noted, however, that consistent-handers show nominally higher scores for both simple and complex WM tasks.

The absence of an association between WM and handedness may reflect the fact that verbal WM tasks are predominantly left hemisphere lateralized (e.g., Nagel, Herting, Maxwell, Bruno, \& Fair, 2013; Wagner, Sziklas, Garver, \& Jones-Gotman, 2009), and although some studies have also shown a bilateral involvement, these are strongly attributed to the use of visual strategies to remember the verbal WM material better (e.g., Gerton et al., 2004; Haut et al., 2000). Given that the handedness differences are presumed to reflect differential access to right hemisphere processes, it may be that the handedness groups do not differ in access to left hemisphere processing.

There are factors that could be addressed in future research. As discussed previously, digit span and LNS are considered to represent simple and complex WM, respectively. However, there is also evidence that shows that the two tests share WM characteristics (e.g., Crowe, 2000). Future research may wish to consider a composite score representing WM. Although this could have been attempted in the current study, the intent was first to show if handedness differences indeed exist between the two WM tasks, and if the three variables were in any capacity contributing to episodic recall.

Given the current findings of the study, and in light of past findings on handedness, WM, and episodic memory, it may be concluded that there is an inconsistent-handed advantage in episodic recall that is not dependent on WM. The independent contribution of handedness therefore needs to be considered in episodic memory studies to better account for individual differences. It has been suggested that the handedness differences in episodic recall arise specifically at retrieval (Christman \& Propper, 2010). Although WM clearly plays a large role in the encoding of episodic memories, it also has been shown to play an important role in retrieval (e.g., Unsworth, 2007) and source monitoring (e.g., Lilienthal, Rose, Tamez, Myerson, \& Hale, 2015). This raises the question of exactly what retrieval processes are related to handedness versus to WM function. Much of the past work on handedness and memory has been primarily empirical, content to simply demonstrate the existence of handedness differences. Studies like the current one will be necessary to start fleshing out the theoretical picture. 


\section{References}

Aben, B., Stapert, S., \& Blokland, A. (2012). About the distinction between working memory and short-term memory. Frontiers in Psychology, 3, 1-9. doi:10.3389/fpsyg.2012.00301

Alipour, A., Aerab-Sheybani, K., \& Akhondy, N. (2012). Effects of handedness and depth of processing on the explicit and implicit memory. Procedia-Social \& Behavioral Sciences, 32, 29-33. doi:10.1016/j. sbspro.2012.01.005

Ashworth, J., Ciorciari, J., \& Stough, C. (2008). Psychophysiological correlates of dissociation, handedness, and hemispheric lateralization. The Journal of Nervous and Mental Disease, 196, 411-416.

Bayliss, D. M., Jarrold, C., Baddeley, A. D., \& Gunn, D. M. (2003). The relationship between short-term memory and working memory: Complex span made simple? Memory, 13, 414-421. doi:10.1080/ 09658210344000332

Bowden, S. C., Petrauskas, V. M., Bardenhagen, F. J., Meade, C. E., \& Simpson, L. C. (2013). Exploring the dimensionality of digit span. Assessment, 20, 188-198. doi:10.1177/1073191112457016

Cabeza, R., Dolcos, F., Graham, R., \& Nyberg, L. (2002). Similarities and differences in the neural correlates of episodic memory retrieval and working memory. NeuroImage, 16, 317-330. doi:10.1006/nimg. 2002.1063

Cabeza, R., Grady, C., Nyberg, L., McIntosh, A., Tulving, E., Kapur, S., . . Craik, F. I. M. (1997). Age related differences in neural activity during memory encoding and retrieval: A positron emission tomography study. The Journal of Neuroscience, 17, 391-400.

Christman, S. D., \& Butler, M. (2011). Mixed-handedness advantages in episodic memory obtained under conditions of intentional learning extend to incidental learning. Brain and Cognition, 77, 17-22. doi: 10.1016/j.bandc.2011.07.003

Christman, S., \& Propper, R. (2010). An interhemispheric basis for episodic memory: Effects of handedness and bilateral eye movements. In G. Davies \& D. Wright (Eds.), Current issues in applied memory (pp. 185-205). London, UK: Psychology Press.

Christman, S. D., Propper, R. E., \& Brown, T. (2006). Increased interhemispheric interaction is associated with earlier offset of childhood amnesia. Neuropsychology, 20, 336-345. doi:10.1037/0894-4105. 20.3.336

Christman, S. D., Propper, R. E., \& Dion, A. (2004). Increased interhemispheric interaction is associated with decreased false memories in a verbal converging semantic associates paradigm. Brain and Cognition, 56, 313-319. doi:10.1016/j.bandc.2004.08.005

Chu, O., Abeare, C. A., \& Bondy, M. A. (2012). Inconsistent vs. consistent right handers' performance on an episodic memory task: Evidence from the California Verbal Learning Test. Laterality: Asymmetries of the Body, Brain, \& Cognition, 17, 306-317. doi: 10.1080/1357650X.2011.568490

Craik, F. I. M., \& McDowd, J. M. (1987). Age differences in recall and recognition. Journal of Experimental Psychology: Learning, Memory, \& Cognition, 13, 474 479. doi:10.1037/0278-7393.13.3.474

Crowe, S. F. (2000). Does the letter number sequencing task measure anything more than digit span? Assessment, 7, 113-117.

Dobbs, A. R., \& Rule, B. G. (1989). Adult age differences in working memory. Psychological Aging, 4, 500-503. doi:10.1037/08827974.4.4.500

Dragovic, M. (2004). Towards an improved measure of the Edinburgh Handedness Inventory: A one-factor congeneric measurement model using confirmatory factor analysis. Laterality, 9, 411-419. doi:10. 1080/13576500342000248

Edlin, J. M., Carris, E. K., \& Lyle, K. B. (2013). Memory for hand-use depends on consistency of handedness. Frontiers in Human Neuroscience, 7, 51-57. doi:10.3389/fnhum.2013.00555
Edlin, J. M., Lappanen, M. L., Fain, R. J., Hacklander, R. P., HanaverTorrez, S. D., \& Lyle, K. B. (2015). On the use (and misuse?) of the Edinburgh Handedness Inventory. Brain and Cognition, 94, 44-51. doi:10.1016/j.bandc.2015.01.003

Egeland, J. (2015). Measuring working memory with digit span and the letter number sequencing subtests from the WAIS-IV: Too low manipulation load and risk of underestimating modality effects. Applied Neuropsychology: Adult, 22, 445-451. doi:10.1080/ 23279095.2014.992069

Friedman, D., \& Johnson, R. (2000). Event-related potential (ERP) studies of memory encoding and retrieval: A selective review. Microscopic Research and Technique, 51, 6-28.

Geffen, G., Moar, K. J., O'Hanlon, A. P., Clark, C. R., \& Geffen, L. B. (1990). Performance measures of 16 to 86-year-old males and females on the Auditory Verbal Learning Test. Clinical Neuropsychologist, 4, 45-63. doi:10.1080/13854049008401496

Gerton, B. K., Brown, T. T., Meyer- Lindenberg, A., Kohn, P., Holt, J. L., Olsen, R. K., \& Berman, K. F. (2004). Shared and distinct neurophysiological components of the digit forward and backward tasks as revealed by functional neuroimaging. Neuropsychologia, 42, 1781-1787. doi:10.1016/j.neuropsychologia.2004.04.023

Gunstad, J., Sptiznagel, M. B., Luyster, F., Cohen, R. A., \& Paul, R. H. (2007). Handedness and cognition across the healthy lifespan. International Journal of Neuroscience, 117, 477-485. doi:10. 1080/00207450600773483

Habib, M., Gayraud, D., Oliva, A., Regis, J., Salamon, G., \& Khalil, R. (1991). Effects of handedness and sex on the morphology of the corpus callosum: A study with brain magnetic resonance imaging. Brain and Cognition, 16, 41-61. doi:10.1016/0278-2626(91) 90084-L

Haut, M. W., Kuwabara, H., Leach, S., \& Arias, R. G. (2000). Neural activation during performance of number-letter sequencing. Applied Neuropsychology, 7, 237-242. doi:10.1207/S15324826AN0704_5

Herlitz, A., Nilsson, L., \& Bäckman, L. (1997). Gender differences in episodic memory. Memory and Cognition, 25(801), 811. doi:10. 3758/BF03211324

Herlitz, A., \& Rehnman, J. (2008). Sex differences in episodic memory. Current Directions in Psychological Science, 17, 52-56. doi:10. 1111/j.1467-8721.2008.00547.x

Hill, B., Elliott, E., Shelton, J., Pella, R., O’Jile, J., \& Gouvier, W. (2010). Can we improve the clinical assessment of working memory? An evaluation of the WAIS-III using a working memory criterion construct. Journal of Clinical and Experimental Neuropsychology, 32, 315-323. doi:10.1080/13803390903032529

Hultsch, D. E., Masson, M. E. J., \& Small, B. J. (1991). Adult age differences in direct and indirect tests of memory. Journal of Gerontology: Psychological Sciences, 46, 22-30. doi:10.1093/ geronj/46.1.P22

Kahana, M. J., Howard, M. W., Zaromb, F., \& Wingfield, A. (2002). Age dissociates of recency and lag recency effects in free recall. Journal of Experimental Psychology: Learning, Memory, and Cognition, 28, 530-540. doi:10.1037/0278-7393.28.3.530

Kahana, M. J., Howard, M. W., \& Polyn, S. M. (2008). Associative retrieval processes in episodic memory. In H. L. Roediger, III (Ed.), Cognitive psychology of memory (Vol. 2, pp. 468-490). Oxford, UK: Elsevier.

Kempe, V., Brooks, P. J., \& Christman, S. D. (2009). Inconsistenthandedness is linked to more successful foreign language vocabulary learning. Psychonomic Bulletin \& Review, 16, 480-485. doi:10. 3758/PBR.16.3.480

Kliegel, R., \& Lindenberger, U. (1993). Modeling intrusions and correct recall in episodic memory: Adult age differences in encoding of list context. Journal of Experimental Psychology: Learning, Memory \& Cognition, 19, 617-637. doi:10.1037/0278-7393.19.3.617

Li, R., Qin, W., Zhang, Y., Jiang, T., \& Yu, C. (2012). The neuronal correlates of digit backward are revealed by voxel based 
morphometry and resting state functional connectivity analyses. PLoS ONE, 7, 1-9. doi:10.1371/journal.pone.0031877

Lilienthal, L., Rose, N. S., Tamez, E., Myerson, J., \& Hale, S. (2015). Individuals with low working memory spans show greater interference from irrelevant information because of poor source monitoring, not greater activation. Memory \& Cognition, 43, 357-366.

Loring-Meier, S., \& Halpern, D. (1999). Sex differences in visuospatial working memory: Components of cognitive processing. Psychonomic Bulletin \& Review, 6, 464-471. doi:10.3758/ BF03210836

Luders, E., Cherbuin, N., Thompson, P. M., Gutman, B., Anstey, K. J., Sachdev, P., \& Toga, A. W. (2010). When more is less: Associations between corpus callosum size and handedness lateralization. NeuroImage, 52, 43-49. doi:10.1016/j.neuroimage.2010.04.016

Lyle, K. B., Hanaver-Torrez, S. D., Hackländer, R. P., \& Edlin, J. M. (2012). Consistency of handedness, regardless of direction, predicts baseline memory accuracy and potential for memory enhancement. Journal of Experimental Psychology: Learning, Memory, and Cognition, 38, 187-193. doi:10.1037/a0024831

Lyle, K. B., McCabe, D. P., \& Roediger, H. L., III. (2008). Handedness is related to memory via hemispheric interaction: Evidence from paired associate recall and source memory tasks. Neuropsychology, 22, 523-530. doi:10.1037/0894-4105.22.4.523

Lynn, R., \& Irwing, P. (2008). Sex differences in mental arithmetic, digit span, and $g$ defined as working memory capacity. Intelligence, 36 , 226-235. doi:10.1016/j.intell.2007.06.002

Myerson, J., Emery, L., White, D. A., \& Hale, S. (2003). Effects of age, domain and processing demands on memory span: Evidence for differential decline. Aging, Neuropsychology \& Cognition, 10, 20 27. doi:10.1076/anec.10.1.20.13454

Nagel, B. J., Herting, M. M., Maxwell, E. C., Bruno, R., \& Fair, D. (2013). Hemispheric lateralization of verbal and spatial working memory during adolescence. Brain and Cognition, 82, 58-68. doi: 10.1016/j.bandc.2013.02.007

Nyberg, L., Marklun, P., Persson, J., Cabeza, R., Forkstam, C., Petersson, K. M., \& Ingvar, M. (2003). Common prefrontal activations during working memory, episodic memory, and semantic memory. Neuropsychologia, 41, 371-377. doi:10.1016/S0028-3932(02) 00168-9

Oldfield, R. C. (1971). The assessment and analysis of handedness: The Edinburgh Inventory. Neuropsychologia, 9, 97-113. doi:10.1016/ 0028-3932(71)90067-4

Parker, A., \& Dagnall, N. (2010). Effects of handedness and saccadic bilateral eye movements on components of autobiographical recollection. Brain and Cognition, 73, 93-101. doi:10.1016/j.bandc. 2010.03.005

Prichard, E., Propper, R. E., \& Christman, S. D. (2013). Degree of handedness, but not direction, is a systematic predictor of cognitive performance. Frontiers in Psychology, 4, 3-6. doi:10.3389/fpsyg.2013. 00009

Propper, R. E., \& Christman, S. D. (2004). Mixed- versus strong righthandedness is associated with biases towards "remember" versus "know" judgments in recognition memory: Role of interhemispheric interaction. Memory, 12, 707-714. doi:10.1037/0894-4105. 20.3.336

Propper, R. E., Christman, S. D., \& Phaneuf, K. A. (2005). A mixed handed advantage in episodic memory: A possible role of interhemispheric interaction. Memory \& Cognition, 33, 751-757. doi:10. 3758/BF03195341

Propper, R. E., Pierce, J., Geisler, M. W., Christman, S. D., \& Bellorado, N. (2012). Asymmetry in resting alpha activity: Effects of handedness. Open Journal of Medical Psychology, 1, 86-90. doi:10.4236/ ojmp.2012.14014

Raaijmakers, J. G. W., \& Shiffrin, R. M. (1981). Search of associative memory. Psychological Review, 88, 93-134. doi:10.1037/0033295X.88.2.93
Ranganath, C., Johnson, M. K., \& D’Esposito, M. (2003). Prefrontal activity associated with working memory and episodic long-term memory. Neuropsychologia, 41, 378-389. doi:10.1016/S00283932(02)00169-0

Salthouse, T. A., \& Babcock, R. L. (1991). Decomposing adult age differences in working memory. Developmental Psychology, 27, 763776. doi:10.1037/0012-1649.27.5.763

Schmidt, H., Jogia, J., Fast, K., Christodoulou, T., Haldene, M., Kumari, V., \& Frangou, S. (2009). No gender differences in brain activation during the $N$-back task: An fMRI study in healthy individuals. Human Brain Mapping, 30, 3609-3615. doi:10.1002/hbm.20783

Shelton, J. T., Elliott, E. M., Hill, B. D., Calamia, M. R., \& Gouvier, W. D. (2009). A comparison of laboratory and clinical working memory tests and their prediction of fluid intelligence. Intelligence, 37, 283 293. doi:10.1016/j.intell.2008.11.005

Spillers, G. J., \& Unsworth, N. (2011). Variation in working memory capacity and temporal-contextual retrieval from episodic memory. Journal of Experimental Psychology, Learning, Memory \& Cognition, 37, 1532-1539. doi:10.1037/a0024852

Tulving, E. (1972). Episodic \& semantic memory. In E. Tulving \& W. Donaldson (Eds.), Organization of memory (pp. 381-403). New York, NY: Academic Press.

Tulving, E. (1993). What is episodic memory? Current Directions in Psychological Science, 2, 67-70. Retrieved from http://www.jstor. org/stable/20182204

Tulving, E., Kapur, S., Craik, F. I. M., Moscovitch, M., \& Houle, S. (1994). Hemispheric encoding/retrieval asymmetry in episodic memory: Positron emission tomography findings. Proceedings of the National Academic Sciences, USA, 91, 2016-2020.

Unsworth, N. (2007). Individual differences in working memory capacity and episodic retrieval: Examining the dynamics of delayed and continuous distractor free recall. Journal of Experimental Psychology, Learning, Memory \& Cognition, 33, 1020-1034. doi:10.1037/02787393.33.6.1020

Unsworth, N., Brewer, G. A., \& Spillers, G. J. (2011). Variation in working memory capacity and episodic memory: Examining the importance of encoding specificity. Psychonomic Bulletin Review, 18, 1113-1118. doi:10.3758/s13423-011-0165-y

Unsworth, N., \& Engle, R. W. (2007). The nature of individual differences in working memory capacity: Active maintenance in primary memory and controlled search from secondary memory. Psychological Review, 114, 104-132. doi:10.1037/0033-295X.114. 1.104

Unsworth, N., \& Spillers, G. J. (2010). Variation in working memory capacity and episodic recall: The contributions of strategic encoding and contextual retrieval. Psychonomic Bulletin Review, 17, 200205. doi:10.3758/PBR.17.2.200

Wagner, D. D., Sziklas, V., Garver, K. E., \& Jones-Gotman, M. (2009). Material-specific lateralization of working memory in the medial temporal lobe. Neuropsychologia, 47, 112-122. doi:10.1016/j. neuropsychologia.2008.08.010

Wechsler, D. (2008). Wechsler adult intelligence scale (4th ed.). San Antonio, TX: Pearson Assessment.

Wechsler, D. (2009). Wechsler memory scale (4th ed.). San Antonio, TX: Pearson Assessment.

Wilde, N. J., Strauss, E., \& Tulsky, D. S. (2004). Memory span on the Wechsler scales. Journal of Clinical and Experimental Neuropsychology, 26, 539-549. doi:10.1080/13803390490496605

Witelson, S. (1985). The brain connection: The corpus callosum is larger in left-handers. Science, 229, 665-668. doi:10.1126/science. 4023705

Witelson, S. F., \& Goldsmith, C. H. (1991). The relationship of hand preference to anatomy of the corpus callosum in men. Brain Research, 545, 175-182. doi:10.1016/0006-8993(91)91284-8 